\title{
Corneal Melanoma
}

National Cancer Institute

\section{Source}

National Cancer Institute. Corneal Melanoma. NCI Thesaurus. Code C4553.

A melanoma within the cornea of the eye. 